\title{
KESESUAIAN DAN DAYA DUKUNG EKOSISTEM MANGROVE UNTUK PENGEMBANGAN EKOWISATA DI PULAU PANNIKIANG, KABUPATEN BARRU, SULAWESI SELATAN
}

\author{
SUITABILITY AND CARRYING CAPACITY OF THE MANGROVE \\ ECOSYSTEM FOR ECOUTURISM DEVELOPMENT AT PANNIKIANG \\ ISLAND, BARRU REGENCY, SOUTH SULAWESI
}

\author{
Rizka Maulidiyah Mas'ud ${ }^{1 *}$, Fredinan Yulianda ${ }^{2}$, \& Gatot Yulianto ${ }^{2}$ \\ ${ }^{1}$ Program Studi Pengelolaan Sumberdaya Pesisir dan Lautan, FPIK-IPB University, Bogor, 16680 \\ ${ }^{2}$ Departemen Manajemen Sumberdaya Perairan, FPIK-IPB University, Bogor, 16680 \\ *E-mail: rizkamaulidiyah3@gmail.com
}

\begin{abstract}
Ecotourism is one of the efforts which can be developed for the sustainability of mangrove ecosystems.This study aims to assess the suitability and carrying capacity of the mangrove ecosystem so it can be used as a reference in making policies. This study was conducted in October-December 2019 at Pannikiang Island, Barru Regency, South Sulawesi Province. The data were analyzed using a matrix of tourism suitability index (IKW), spatial analysis with a Geographic Information System (GIS) approach followed by an assessment of the carrying capacity of the region (DDK) to determine the maximum number of visitors that could be accommodated. The result shows that the IKW of the study location with highly suitable is $6.73 \mathrm{ha}$ and 22.03 ha fall into the appropriate category so that the total IKW obtained was $28.76 \mathrm{ha}$. The length area that can be utilized for tracking activity is $1793.45 \mathrm{~m}$ with the carrying capacity of mangrove ecotourism is 287 people/day with consideration of the tourism duration for each visitor (open 8 hours/day). Pannikiang Island as a whole is included in the appropriate category for ecotourism with a capacity of tourists in the good category and does not exceed the maximum threshold allowed. Therefore, the recommendation for policy submission is supposed to set down the regulations regarding mangrove ecosystem management.
\end{abstract}

Keywords: carrying capacity, ecotourism, mangrove ecosystem, suitability

\begin{abstract}
ABSTRAK
Ekowisata adalah salah satu upaya yang dapat dikembangkan untuk keberlanjutan ekosistem mangrove. Penelitian ini bertujuan untuk menilai kesesuaian dan daya dukung ekosistem mangrove sehingga dapat dijadikan sebagai bahan acuan dalam pengambilan kebijakan pengelolaan ekosistem mangrove. Penelitian ini dilakukan pada bulan Oktober-Desember 2019 di Pulau Pannikiang, Kabupaten Barru, Provinsi Sulawesi Selatan. Data dianalisis dengan menggunakan matriks analisis Indeks Kesesuaian Wisata (IKW), analisis secara spasial dengan pendekatan Sistem Informasi Geografis (SIG) yang dilanjutkan dengan penilaian Daya Dukung Kawasan (DDK) untuk menentukan jumlah maksimum pengunjung yang dapat ditampung. Hasil penelitian menunjukkan bahwa IKW di lokasi penelitian dengan kategori sangat sesuai 6,73 ha dan 22,03 ha yang masuk dalam kategori sesuai sehingga total IKW yang diperoleh 28,76 ha. Panjang area yang dapat dimanfaatkan untuk kegiatan tracking adalah 1793,45 m dan daya dukung ekowisata mangrove adalah 287 orang/hari dengan pertimbangan lama waktu berwisata setiap pengunjung (buka 8 jam/hari). Pulau Pannikiang secara keseluruhan masuk dalam kategori sesuai untuk ekowisata dengan kapasitas daya tampung wisatawan dalam kategori baik dan tidak melebihi ambang batas maksimal yang diperbolehkan. Oleh karena itu, rekomendasi pengambilan kebijakan yang disarankan adalah membuat peraturan terkait pengelolaan ekosistem mangrove.
\end{abstract}

Kata kunci: daya dukung, ekowisata, ekosistem mangrove, kesesuaian 


\section{PENDAHULUAN}

Pulau Pannikiang merupakan salah satu dari beberapa pulau-pulau kecil yang berada di Kabupaten Barru yang ditunjuk sebagai pencadangan kawasan konservasi perairan berdasarkan Surat Keputusan Gubernur Sulawesi Selatan Nomor 2944 Tahun 2018. Penunjukan pulau ini merupakan langkah strategis dan penting sebagai upaya perlindungan terhadap sumber daya alam yang masih tergolong alami dengan berbagai macam fungsi. Pulau Pannikiang memiliki beberapa ekosistem salah satunya ekosistem mangrove. Luas ekosistem mangrove di Pulau Pannikiang sekitar 86,31 ha tersebar dihampir sepanjang Pulau Pannikiang.

Ekosistem mangrove merupakan salah satu sumber daya alam yang produktif di dunia (Kathiresan \& Bingham, 2001) dan memiliki peran penting dalam menjaga keseimbangan ekosistem. Hal ini sesuai dengan penelitian Veettil et al. (2018) bahwa ekosistem mangrove Vietnam merupakan ekosistem yang paling produktif dan penting secara biologis serta berfungsi sebagai habitat untuk spesies ikan komersial dan non komersial. Nagelkerken et al. (2008) mengatakan bahwa ekosistem mangrove berfungsi sebagai habitat dari berbagai biota seperti kepiting, udang, dan ikan. Selain itu, ekosistem mangrove memberikan manfaat bagi masyarakat melalui kegiatan ekowisata pesisir (Wardhani, 2011; Heriyanto \& Subiandono, 2012). Potensi ekosistem mangrove baik dari segi ekologi maupun dari segi produk olahan dapat menjadi daya tarik tersendiri bagi wisatawan.

Pulau Pannikiang memiliki bentuk daratan memanjang dari arah Utara-Selatan. Kurang lebih sepanjang 3,08 km pulau ini sebagai pemecah gelombang dan pelindung sebagian pantai dan pelabuhan garongkong di Kabupaten Barru dari abrasi (DKP Provinsi Sulawesi Selatan dan Universitas Muslim Indonesia, 2012) serta memiliki hamparan ekosistem mangrove yang cukup luas dan lebat dengan keanekaragaman jenis mangrove yang lengkap. Identifikasi jenis mangrove di Pulau Pannikiang telah dilakukan oleh beberapa peneliti sebelumnya yaitu 19 famili 30 jenis (Suwardi et al., 2013), 6 famili 8 jenis (Samsi et al., 2018) dan 6 famili 11 jenis (Rusdi et al., 2020). Berbagai jenis biota seperti kelelawar, krustasea, moluska, jenis ikan, burung dan berbagai jenis biota yang hidup berasosiasi di kawasan ini. Dibalik potensi sumber daya alam yang menjanjikan di Pulau Pannikiang, ternyata status keberlanjutan ekosistem mangrove di Pulau Pannikiang tergolong kurang berkelanjutan. Hal tersebut dikarenakan belum adanya pengelolaan secara baik dari pihak pemerintah setempat (Rusdi et al., 2020) dikhawatirkan dampak negatif yang akan timbul.

Menurut data Food and Agriculture Organisation (FAO) pada tahun 2007 dalam tiga dekade terakhir, Indonesia kehilangan sekitar $40 \%$ ekosistem mangrove dan kerusakan mangrove di dunia telah mencapai sekitar $46 \%$ dalam beberapa dekade terakhir (Romañach et al., 2018). Giri et al. (2010) mengatakan bahwa ekosistem mangrove di seluruh dunia menghadapi sejumlah ancaman seperti polusi, deforestasi (penebangan hutan), dan fragmentasi (perubahan lingkungan). Oleh karenanya, perlu upaya yang inovatif dalam pemanfaatan potensi ekosistem mangrove untuk meningkatkan kesejahteraan masyarakat setempat dengan tetap menjaga kelestarian ekosistem.

Menurut beberapa penduduk dan pemangku kepentingan menyatakan bahwa keberadaan ekosistem mangrove di kawasan ini belum banyak memberikan manfaat secara langsung untuk meningkatkan kesejahteraan masyarakat setempat. Hal ini disebabkan rendahnya pemahaman masyarakat setempat terhadap pentingnya kelestarian ekosistem mangrove secara langsung maupun tidak langsung, kurangnya sarana dan prasarana yang memadai sehingga memicu terjadinya pemanfaatan yang tidak terkendali dan menyebabkan kerusakan seperti pene- 
bangan mangrove untuk dijadikan kayu bakar. Agar upaya konservasi tetap berkelanjutan maka konsep ekowisata sangat diperlukan.

Konsep ekowisata berkembang pada tahun 1970-an sebagai reaksi terhadap kerusakan lingkungan dan sosial yang disebabkan oleh pariwisata massal tanpa mempertimbangkan dampak yang terjadi (Honey \& Krantz, 2007). Ekowisata merupakan pembelajaran ekologi yang dapat dimplementasikan untuk pengembangan ekosistem mangrove (Surjanti et al., 2020). Dengan pendekatan ekowisata, masyarakat dapat memanfaatkan keindahan alam yang masih alami tanpa merusak ekosistem. Hal ini sejalan dengan penelitian Spalding \& Parrett (2019) yang menyebutkan bahwa ekowisata mangrove dapat menarik puluhan hingga ratusan juta pengunjung setiap tahunnya dan meningkatkan pendapatan serta partisipasi masyarakat lokal dalam pengelolaan ekowisata (Shoo \& Songorwa, 2013). Penelitian serupa telah dilakukan oleh Rini et al. (2008) bahwa ekowisata dapat mendukung strategi pertumbuhan agresif (growth oriented strategy) sebagai salah satu alternatif kegiatan pemanfaatan ruang pesisir yang dapat menunjang kegiatan konservasi serta dipandang secara luas dan sangat penting karena memiliki dampak positif bagi lingkungan, masyarakat dan kawasan konservasi dengan mengambil langkahlangkah untuk meminimalkan kerusakan dampak lingkungan, menghasilkan manfaat yang signifikan (Buckley, 2004) yang dapat membuka alternatif pertumbuhan ekonomi/ mata pencaharian alternatif bagi masyarakat setempat. Friess (2016) berpendapat jika ekowisata ingin berhasil, hal yang penting dilakukan yakni memitigasi dampak lingkungan langsung dari peningkatan jumlah wisatawan dan Gigović et al. (2016) menggunakan sistem pendekatan zonasi dengan penerapan model GIS-FDEMATEL MCDA yang melihat tingkat kesesuaian dalam konsep ekowisata. Oleh karena itu, penelitian secara umum bertujuan mengembangkan ekowisata mangrove untuk mengurangi dampak negatif yang akan terjadi dengan memperhatikan parameter kesesuaian lahan dan daya dukung kawasan.

\section{METODE PENELITIAN}

\subsection{Waktu dan Lokasi Kegiatan}

Penelitian dilakukan di kawasan ekosistem mangrove Pulau Pannikiang, Kabupaten Barru, Provinsi Sulawesi Selatan, pada bulan Oktober-Desember 2019. Pengambilan sampel dibagi menjadi 4 stasiun (Figure 1). Penentuan titik stasiun di-lakukan dengan metode purposive sampling.

\subsection{Metode Pengumpulan Data}

Data yang akan digunakan dalam penelitian ini terdiri dari data primer dan sekunder. Data primer adalah data yang dikumpulkan melalui pengamatan langsung (wawancara dan sampling mangrove) di lapangan, hal ini bertujuan untuk melakukan penentuan titik stasiun pengamatan dengan menggunakan alat bantu Global Positioning System (GPS). Data primer yang dikumpulkan berupa pemantauan terhadap ekosistem mangrove seperti ketebalan mangrove (m) dengan menggunakan analisis citra Google Earth Pro 7.3.2.5776 (64-bit) yang dibuat oleh Keyhole Inc (AS), kerapatan mangrove (ind $/ \mathrm{m}^{2}$ ) dengan menggunakan tali dan meteran dengan metode transek kuadrat (Bengen, 2001) yang diletakkan tegak lurus garis pantai menuju daratan sebaran mangrove, identifikasi jenis mangrove menggunakan buku panduan mangrove (Noor et al., 1999), pengamatan biota dilakukan bersamaan dengan kegiatan sampling data vegetasi mangrove dengan metode pengamatan langsung. Data sekunder dikumpulkan dari data-data hasil penelitian sebelumnya dan data dari instansi terkait. Data sekunder yang dikumpulkan berupa data pasang surut (m) diperoleh dari tides.big.go.id, kondisi umum lokasi penelitian diperoleh dari instansi terkait serta beberapa riset mengenai 


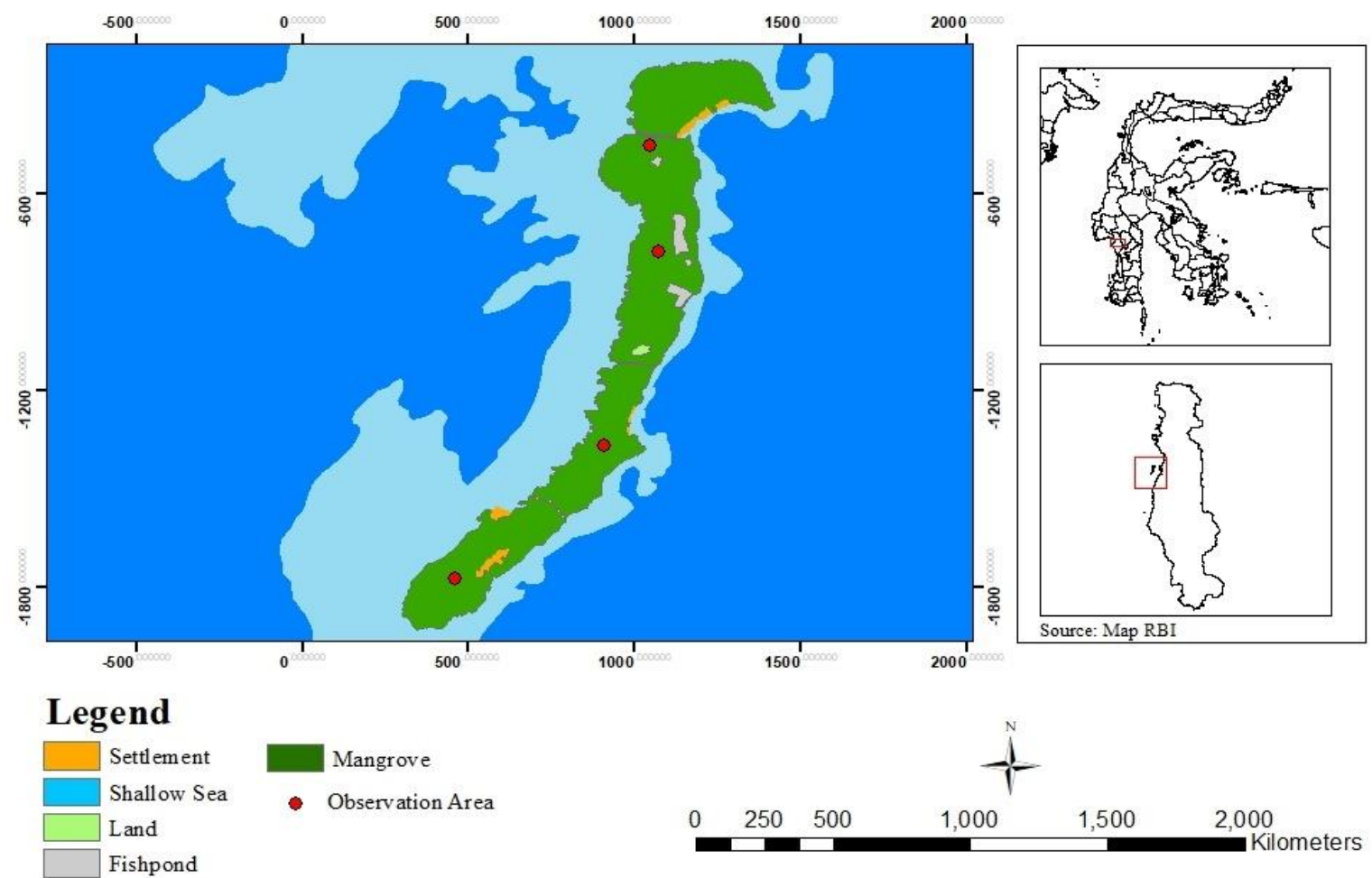

Figure 1. Research station on Pannikiang Island.

potensi sumber daya alam di Pulau Pannikiang.

\subsection{Analisis Data}

Analisis kesesuaian untuk ekowisata mangrove dimodelkan secara spasial dengan pendekatan Sistem Informasi Geografis (GIS) sejalan dengan pendapat Kalogirou (2001) dan Hossain et al. (2008) menyatakan bahwa SIG dapat berfungsi untuk mengolah data spasial dan 2 visualisasi hasil analisis kesesuaian. Langkah-langkah yang dilakukan diantaranya: (1) mendeliniasi citra sentinel 2A dengan resolusi spasial $10 \mathrm{~m}$ untuk batas lahan daratan dan perairan, (2) menganalisis secara spasial titik lokasi yang diperoleh saat survei, (3) melakukan input data in situ ke dalam peta, (4) selanjutnya memasukkan nilai hasil perkalian antara bobot dan skor pada atribut masing-masing fitur yang telah terbentuk untuk memperoleh lokasi yang sesuai. Analisis spasial dilakukan dengan menggunakan software ArcGIS
10.4.1 dengan teknik spasial overlay modelling yang menggunakan pembobotan pada sejumlah faktor yang berpengaruh dan skor kesesuaian pada setiap kriteria yang telah ditentukan. Analisis yang digunakan lebih lengkap sebagai berikut:

\subsubsection{Indeks Kesesuaian Wisata (IKW)}

Analisis kesesuaian wisata mangrove dilakukan dengan pendekatan pengukuran kualitas sumber daya mangrove yang menjadi objek ekowisata sehingga untuk mengetahui penilaian kesesuaian ekowisata mangrove dapat menggunakan rumus sebagai berikut (Yulianda, 2019):

$I K W=\sum_{i=1}^{n}(B i x S i)$

Keterangan: $n=$ Banyaknya parameter kesesuaian, $B_{i}=$ Bobot parameter ke-i, dan $S_{i}=$ Skor parameter ke-i.

Parameter yang diukur dalam kesesuaian wisata diantaranya ketebalan mang- 
rove $(\mathrm{m})$, kerapatan mangrove (ind/100 $\mathrm{m}^{2}$ ), jenis mangrove, pasang surut (m), objek biota ditentukan dengan menggunakan matriks kesesuaian dan diklasifikasikan menjadi 3 (tiga) kelas kesesuaian yaitu sangat sesuai (S1), sesuai (S2), tidak sesuai (S3) (Yulianda, 2019) (Table 1).

Penilaian dilakukan berdasarkan perkalian antara bobot dan skor, yang selanjutnya dilakukan penggabungan beberapa variabel untuk menetapkan kelas kesesuaian. Nilai dari indeks kesesuaian wisata yang didapat kemudian disesuaikan dengan kategori, IKW $\geq 2,5=$ Sangat sesuai; $2,0 \leq \mathrm{IKW}$ $<2,5=$ Sesuai; $1 \leq \mathrm{IKW}<2,0=$ Tidak sesuai; IKW $<1=$ Sangat tidak sesuai.

\subsubsection{Daya Dukung Kawasan (DDK)}

Perhitungan Daya Dukung Kawasan (DDK) diperlukan untuk menentukan jumlah maksimum pengunjung yang dapat di- tampung di kawasan yang disediakan tanpa menimbulkan gangguan pada alam dan manusia. Perhitungan DDK dapat menggunakan rumus (Yulianda, 2019) sebagai berikut:

$\mathrm{DDK}=\mathrm{K}_{\mathrm{X}}\left(\frac{\mathrm{Lp}}{\mathrm{Lt}}\right) \mathrm{x}\left(\frac{\mathrm{Wt}}{\mathrm{Wp}_{\mathrm{p}}}\right)$

Keterangan: $D D K=$ Daya Dukung Kawasan Wisata (orang/hari), $K=$ Potensi ekologis pengunjung per satuan unit area (orang), $L p=$ Luas area $\left(\mathrm{m}^{2}\right)$ atau panjang area $(\mathrm{m})$ yang dapat dimanfaatkan, $L t=$ Unit area untuk kategori tertentu $\left(\mathrm{m}^{2}\right.$ atau $\left.\mathrm{m}\right), W t=$ Waktu yang disediakan oleh kawasan untuk kegiatan wisata dalam 1 hari (jam), $W p=$ Waktu yang dihabiskan oleh pengunjung untuk setiap kegiatan tertentu (jam).

Waktu kegiatan pengunjung (Wp) dihitung berdasarkan lamanya waktu yang

Table 1. The matrix of suitability category of mangrove ecotourism.

\begin{tabular}{|c|c|c|c|}
\hline Parameter & Weight & Category & Score \\
\hline \multirow[t]{4}{*}{ Mangrove thickness $(\mathrm{m})$} & 0.380 & $>500$ & 3 \\
\hline & & $>200-500$ & 2 \\
\hline & & $50>200$ & 1 \\
\hline & & $<50$ & 0 \\
\hline \multirow{4}{*}{$\begin{array}{l}\text { Mangrove density } \\
\left(\text { ind } / 100 \mathrm{~m}^{2}\right)\end{array}$} & 0.250 & $>15-20$ & 3 \\
\hline & & $>10-15 ;>20$ & 2 \\
\hline & & $5-10$ & 1 \\
\hline & & $<5$ & 0 \\
\hline \multirow[t]{4}{*}{ Mangrove species } & 0.150 & $>5$ & 3 \\
\hline & & $3-5$ & 2 \\
\hline & & $1-2$ & 1 \\
\hline & & 0 & 0 \\
\hline \multirow{4}{*}{ Tidal (m) } & 0.120 & $0-1$ & 3 \\
\hline & & $3-4$ & 2 \\
\hline & & $>2-5$ & 1 \\
\hline & & $>5$ & 0 \\
\hline \multirow[t]{4}{*}{ Biota Object } & 0.100 & $\begin{array}{c}\text { Fish. Shrimp. Crab. Mollusk. Reptile. } \\
\text { Bird }\end{array}$ & 3 \\
\hline & & Fish. Shrimp. Crab. Mollusk & 2 \\
\hline & & Fish. Mollusk & 1 \\
\hline & & One of aquatic biota & 0 \\
\hline
\end{tabular}

Source: Yulianda (2019). 
Table 2. Ecological potential of mangrove ecotourism visitor.

\begin{tabular}{lcccc}
\hline Activity & $\mathrm{K}\left(\sum\right.$ visitor $)$ & Lt (area) & Wp (hour) & Wt (hour) \\
\hline $\begin{array}{l}\text { Mangrove } \\
\text { Ecotourism }\end{array}$ & 1 & $\begin{array}{l}25 \mathrm{~m} \text { (calculated length of the path, } \\
\text { every 1 person along the } 25 \mathrm{~m})\end{array}$ & 2 & 8 \\
\hline
\end{tabular}

Source: Yulianda (2019).

dihabiskan oleh pengunjung untuk menikmati keindahan yang ditawarkan oleh sumber daya. Waktu pengunjung diperhitungkan untuk meminimalisir gangguan pada sumber daya alam dengan waktu yang disediakan kawasan (Wt) yaitu lama waktu areal dibuka dalam satu hari untuk kegiatan wisata (Table 2).

\section{HASIL DAN PEMBAHASAN}

\subsection{Kondisi Ekosistem Mangrove}

Ekosistem mangrove di Pulau Pannikiang pada umumnya didominasi oleh jenis Rhizophora apiculata, Rhizophora mucronata dan Sonneratia alba. Sebaran ekosistem mangrove di Pulau Pannikiang dikategorikan sangat sesuai dan sesuai dengan melihat beberapa parameter. Kondisi ekosistem mangrove Pulau Pannikiang saat ini dalam kategori baik dengan tingkat kepadatan 72,86 ha berdasarkan pengukuran SIG (Table 3). Kondisi mangrove tidak banyak berubah sejak tahun 2011 dengan kondisi ekosistem mangrove di Pulau Pannikiang kategori sedang hingga lebat serta masih dalam kategori baik (DKP Provinsi Sulawesi Selatan, 2011). Selain itu, terdapat beberapa pohon asosiasi yang tumbuh di sekitar mangrove seperti Hibiscus tiliaceus, Pandanus amaryllifolius, dan Terminalia catappa terutama yang dekat dengan kawasan pemukiman seperti yang dikemukakan oleh Suwardi et al. (2013). Secara keseluruhan ekosistem mangrove di Pulau Pannikiang tumbuh lebat dengan struktur sedimen dasar di daerah pantai umumnya berpasir halus hingga kasar kehitam-hitaman dan berlumpur. Hal ini membuat sebagian besar wilayah Pulau
Pannikiang ditumbuhi oleh mangrove.

Table 3. Condition of mangrove on Pannikiang Island.

\begin{tabular}{clc}
\hline No. & Mangrove Conditions & Large (ha) \\
\hline 1 & Rarely & 2.04 \\
2 & Medium & 18.88 \\
3 & Solid & 72.86 \\
\hline Total & 93.78 \\
\hline
\end{tabular}

\subsection{Ketebalan Mangrove (m)}

Ketebalan mangrove merupakan salah satu parameter yang sangat penting dalam mengembangkan ekowisata mangrove. Perhitungan ketebalan mangrove dilakukan dengan menggunakan citra satelit Google Earth. Ketebalan mangrove Pulau Pannikiang di setiap stasiun berkisar 155$319 \mathrm{~m}$ dengan rata-rata $249 \mathrm{~m}$, berbeda dengan hasil penelitian Sadik et al. (2017) di kawasan mangrove Gonda Desa Laliko, Kabupaten Polewali mandar yang memperoleh nilai ketebalan mangrove 145-212 $\mathrm{m}$ dengan rata-rata $188 \mathrm{~m}$. Menurut Rini et al. (2018) di kawasan mangrove Lantebung Kota Makassar menunjukkan ketebalan mangrove 119-163 m dengan rata-rata 144,5 $\mathrm{m}$. Adanya perbedaan ketebalan mangrove akan memberikan dampak terhadap aspek biologis di kawasan mangrove. Ketebalan mangrove di setiap stasiun termasuk dalam kategori sesuai (S2) untuk wisata berdasarkan kriteria Yulianda (2019) (Table 4).

\subsection{Jenis dan Kerapatan Mangrove (ind $/ \mathbf{m}^{2}$ )}

Identifikasi jenis mangrove di Pulau Pannikiang telah dilakukan oleh peneliti 
Table 4. Mangrove thickness of each research station.

\begin{tabular}{ccccc}
\hline Stations & \multicolumn{2}{c}{ Coordinate } & $\begin{array}{c}\text { Mangrove } \\
\text { thickness }(\mathrm{m})\end{array}$ & Criteria* \\
\hline 1 & $\mathrm{~S}: 4^{\circ} 20^{\prime} 30.93^{\prime \prime}$ & $\mathrm{E}: 119^{\circ} 35^{\prime} 59.43^{\prime \prime}$ & 299 & Score 2 \\
2 & $\mathrm{~S}: 4^{\circ} 20^{\prime} 58.32^{\prime \prime}$ & $\mathrm{E}: 119^{\circ} 35^{\prime} 59.18^{\prime \prime}$ & 319 & Score 2 \\
3 & $\mathrm{~S}: 4^{\circ} 21^{\prime} 17.24^{\prime \prime}$ & $\mathrm{E}: 119^{\circ} 35^{\prime} 55.02^{\prime \prime}$ & 155 & Score 1 \\
4 & $\mathrm{~S}: 4^{\circ} 21^{\prime} 37.18^{\prime \prime}$ & $\mathrm{E}: 119^{\circ} 35^{\prime} 39.16^{\prime \prime}$ & 222 & Score 2 \\
\hline
\end{tabular}

*Criteria according to Yulianda (2019).

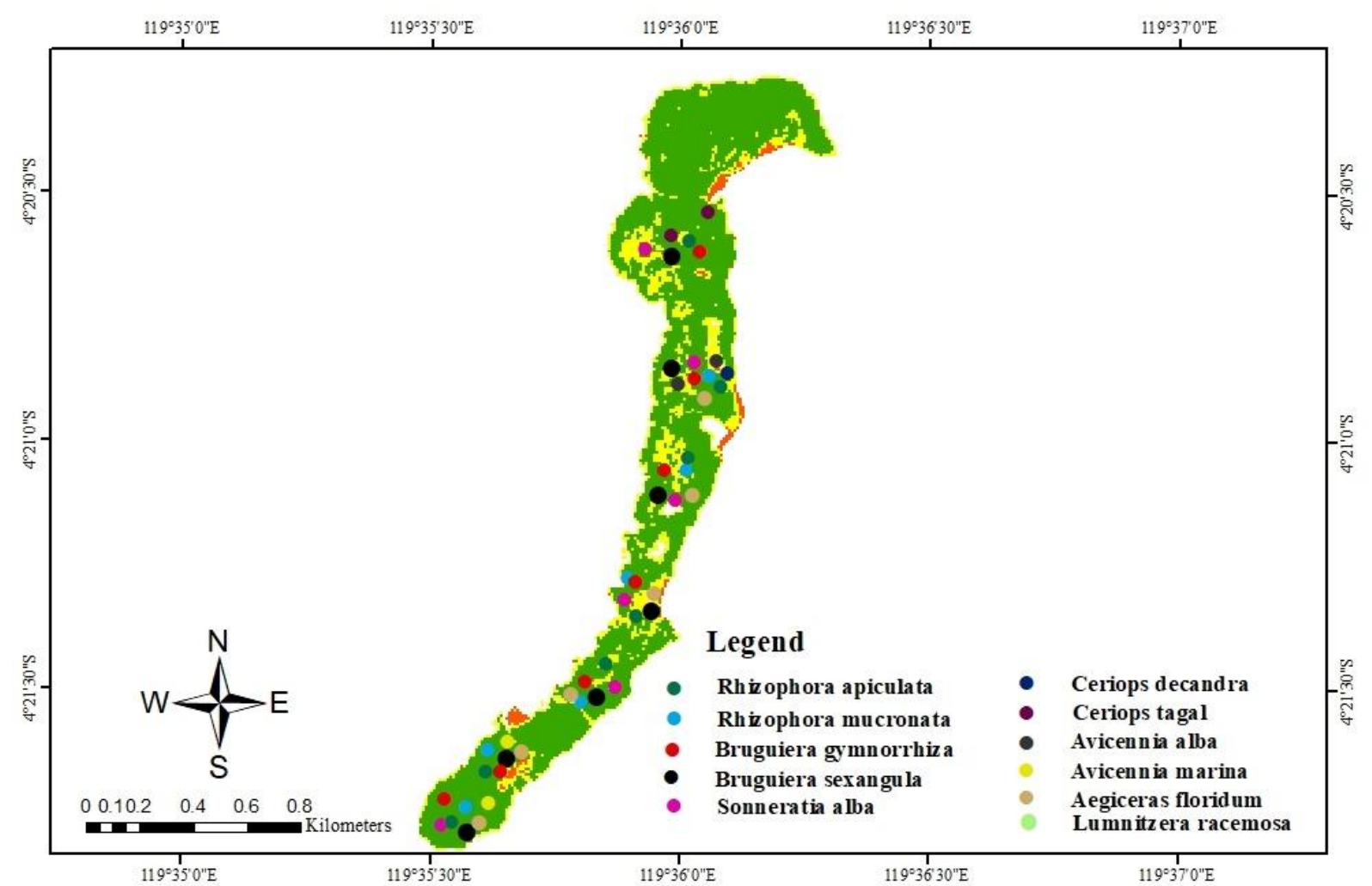

Figure 2. Distribution of mangrove species.

sebelumnya yaitu 19 famili 30 jenis (Suwardi et al., 2013), 6 famili 8 jenis (Samsi et al., 2018), 6 famili 11 jenis (Rusdi et al., 2020). Ekosistem mangrove yang ditemukan di Pulau Pannikiang, Kabupaten Barru, Provinsi Sulawesi Selatan ditemukan 5 famili yaitu Avicenniaceae, Rhizophoraceae, Combretaceae, Sonneratiaceae, Myrsinaceae dan 11 jenis mangrove yaitu $R$. apiculata, $R$. mucronata, Bruguiera gymnorrhiza, B. sexangula, $C$. tagal, $C$. decandra, S. alba, A. floridum, L. racemosa, Avicennia marina dan A. alba (Figure 2).
Hal ini sejalan dengan penelitian sebelumnya, bahwa jenis mangrove yang dominan di Pulau Pannikiang adalah Famili Rhizophoraceae. Perbedaan jenis yang ditemukan diduga lokasi area penelitian yang berbeda dan penempatan setiap plot transek yang berbeda pula.

Kerapatan mangrove salah satu parameter ekologi ekosistem mangrove yang menunjukkan kesuburan vegetasi mangrove. Menurut Yulius et al. (2018) mengatakan bahwa kerapatan mangrove penting dalam menunjukkan bahwa komunitas ekosistem 


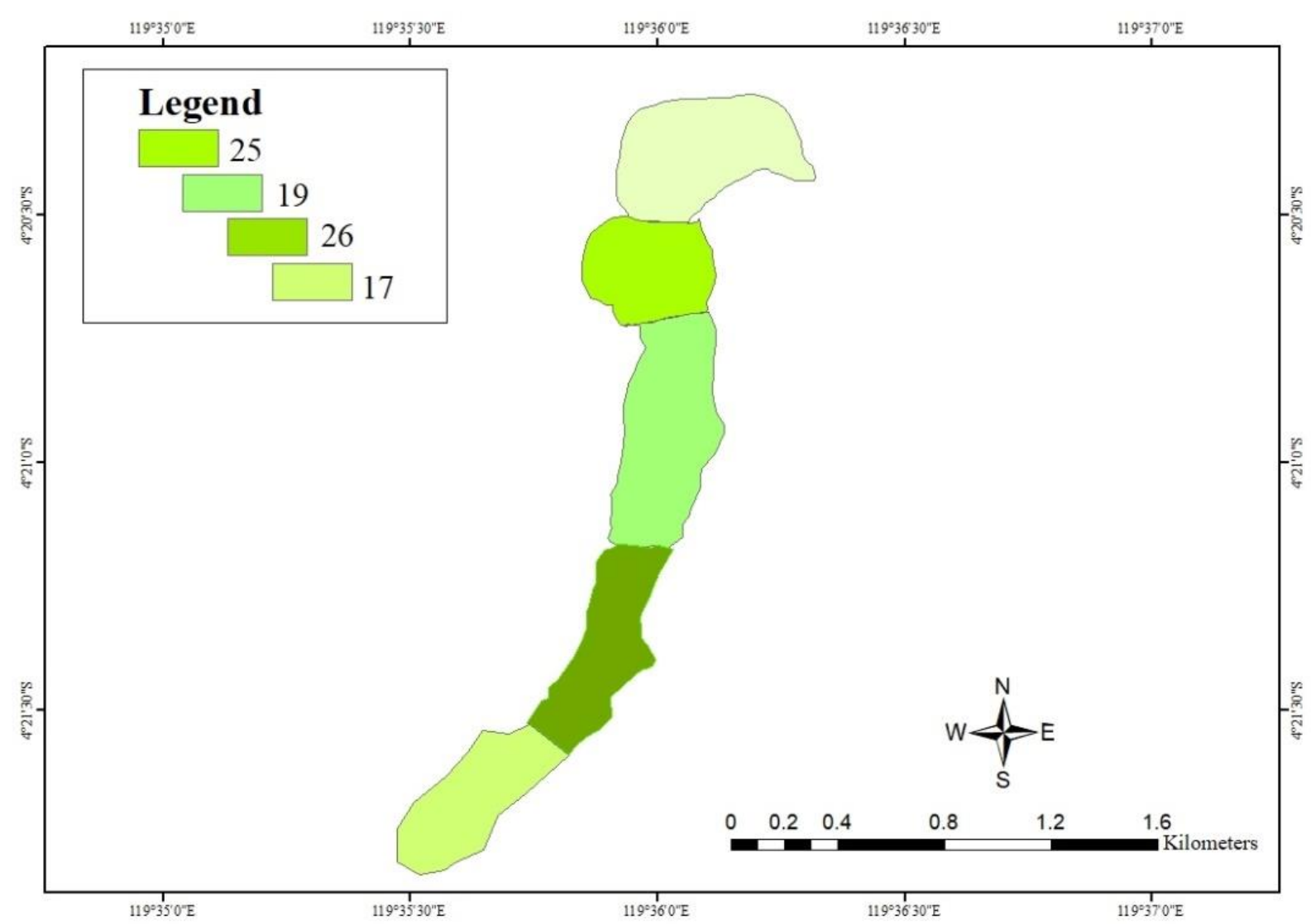

Figure 3. Distribution of mangrove density $\left(\mathrm{ind} / \mathrm{m}^{2}\right)$.

mangrove yang ada tumbuh pada perairan yang subur. Kerapatan mangrove pada beberapa titik stasiun pengamatan memiliki kerapatan yang tinggi dibandingkan dengan beberapa titik stasiun lainnya dikarenakan pola adaptasi setiap individu mangrove berbeda-beda dan dipengaruhi oleh banyak faktor. Perbedaan kerapatan mangrove di masing-masing area penelitian dipengaruhi oleh beberapa faktor, diantaranya adaptasi mangrove terhadap lingkungan atau habitat, kondisi substrat dan lain sebagainya (Figure 3). Kondisi mangrove dipengaruhi oleh beberapa faktor salah satu diantaranya ialah kegiatan manusia (Rakotomavo \& Fromard, 2010; Susi et al., 2018).

Berdasarkan matriks kesesuaian Yulianda (2019), nilai kerapatan mangrove $>15-20$ ind $/ 100 \mathrm{~m}^{2}$ (score 3), >10-15 ind/100 $\mathrm{m}^{2}$ (score 2), >15-20 ind/100 $\mathrm{m}^{2}$ (score 2), $<5$ ind $/ 100 \mathrm{~m}^{2}$ (score 1 ). Kondisi mangrove berdasarkan parameter kerapatan mangrove, sebagian besar mangrove di Pulau Pannikiang masuk dalam kategori sangat sesuai (score 3) pada ekowisata mangrove.

\subsection{Pasang Surut (m)}

Pasang surut merupakan salah satu faktor fisik yang memengaruhi ekosistem mangrove. Pariwono (2007) mengemukakan bahwa pasang surut merupakan proses naik dan turunnya paras laut secara periodik yang disebabkan oleh gaya tarik benda-benda angkasa. Penilaian pasang surut diperlukan untuk kegiatan tracking. Ekosistem mangrove akan sulit untuk dikunjungi wisatawan apabila air laut pasang, akan tetapi berguna untuk kegiatan diluar tracking mangrove seperti kegiatan photography. Sebaliknya, apabila air laut surut kegiatan tracking akan lebih mudah. Hasil analisis data tipe pasang surut tahun 2019 di Pulau Pannikiang menunjukkan pasang surut tipe campuran 
condong harian ganda (Mixed mainly semidiurnal tidel). Tipe ini didapatkan dari hasil analisis perhitungan pasang surut bulanan (Figure 4).

Hasil perhitungan data selama bulan Januari-Oktober 2019 nilai rata-rata yang dihasilkan ialah 1,41 m. Berdasarkan parameter kesesuaian ekowisata mangrove Yulianda (2019), nilai pasang surut di Pulau Pannikiang masuk dalam kategori sesuai (score 2) dengan kategori pasang surut dengan nilai >1-2 untuk kegiatan ekowisata.

\subsection{Potensi Biota}

Pulau Pannikiang memiliki tingkat keanekaragaman hayati yang tinggi, diantaranya ribuan kelelawar, berbagai jenis burung yang masuk dalam kategori dilindungi (Figure 5). Hasil penelitian menunjukkan bahwa beberapa jenis burung menjadikan ekosistem mangrove sebagai habitatnya. Hal ini sejalan dengan penelitian Noor et al. (1999) bahwa bangau (Famili:
Ciconiidae), pecuk (Famili: Phalacrocoracidae) dan kuntul (Genus: Egretta spp.) menjadikan mangrove sebagai habitat untuk mencari makanan dan berkembang biak.

Fungsi lain dari ekosistem mangrove ialah sebagai tempat pemijahan (spawning grounds), tempat pengasuhan (nursery grounds) dan tempat mencari makan (feeding grounds) berbagai jenis ikan, kepiting, moluska dan biota lainnya. Menurut Samsi et al. (2018) tidak hanya dihuni oleh jenis-jenis burung tetapi terdapat jenis kelelawar, ikan, kepiting, moluska yang berasosiasi dengan ekosistem mangrove di Pulau Pannikiang. Biota yang ditemukan di kawasan mangrove Pulau Pannikiang disajikan pada (Figure 6).

Potensi biota yang ditemukan di Pulau Pannikiang masuk dalam kategori sangat sesuai (S1) dengan nilai (score 3) untuk ekowisata berdasarkan matriks kesesuaian ekowisata mangrove Yulianda (2019).

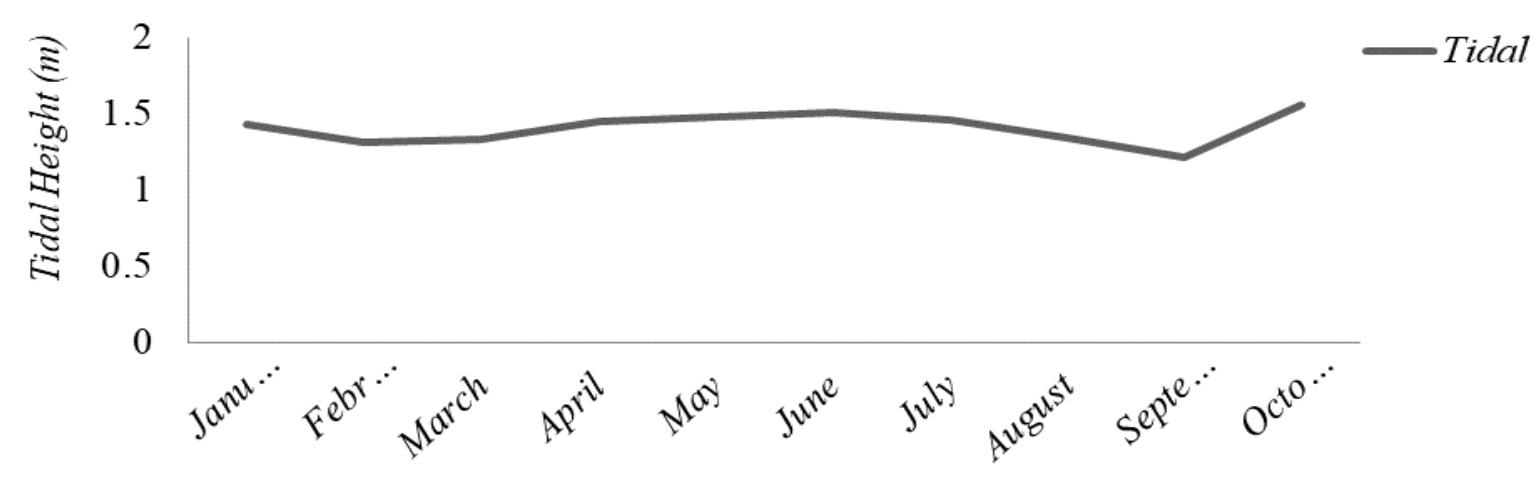

Figure 4. Tides on the Pannikiang Island period January-October 2019.
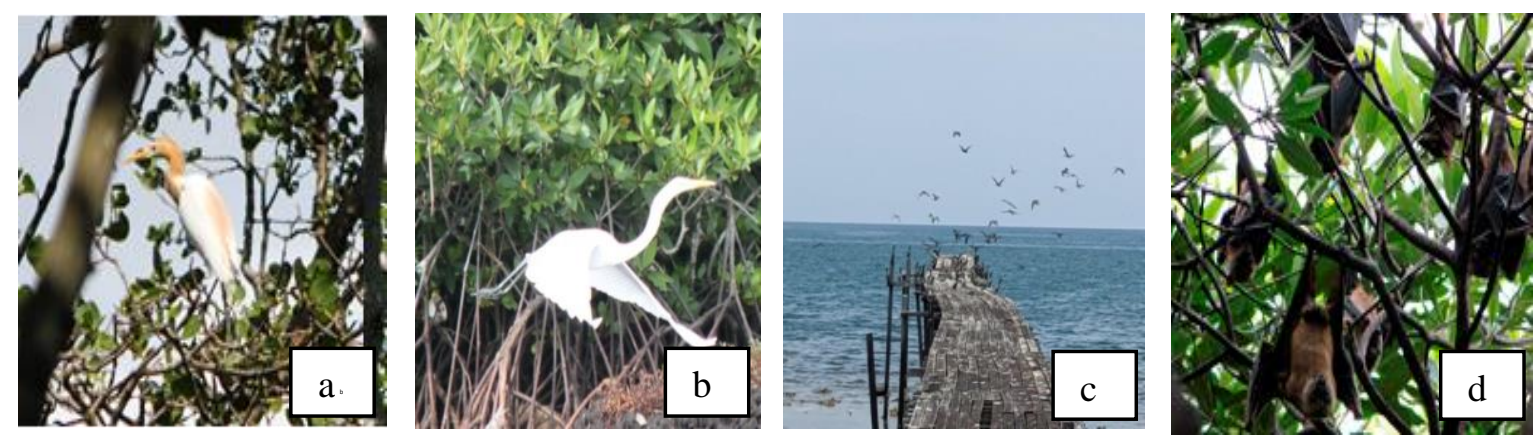

Figure 5. Type of biota found in mangrove ecosystem (a) Bubulcus ibis, (b) Phalacrocorax melanoleucos, (c) Egretta alba, (d) Acerodon celebensis. 

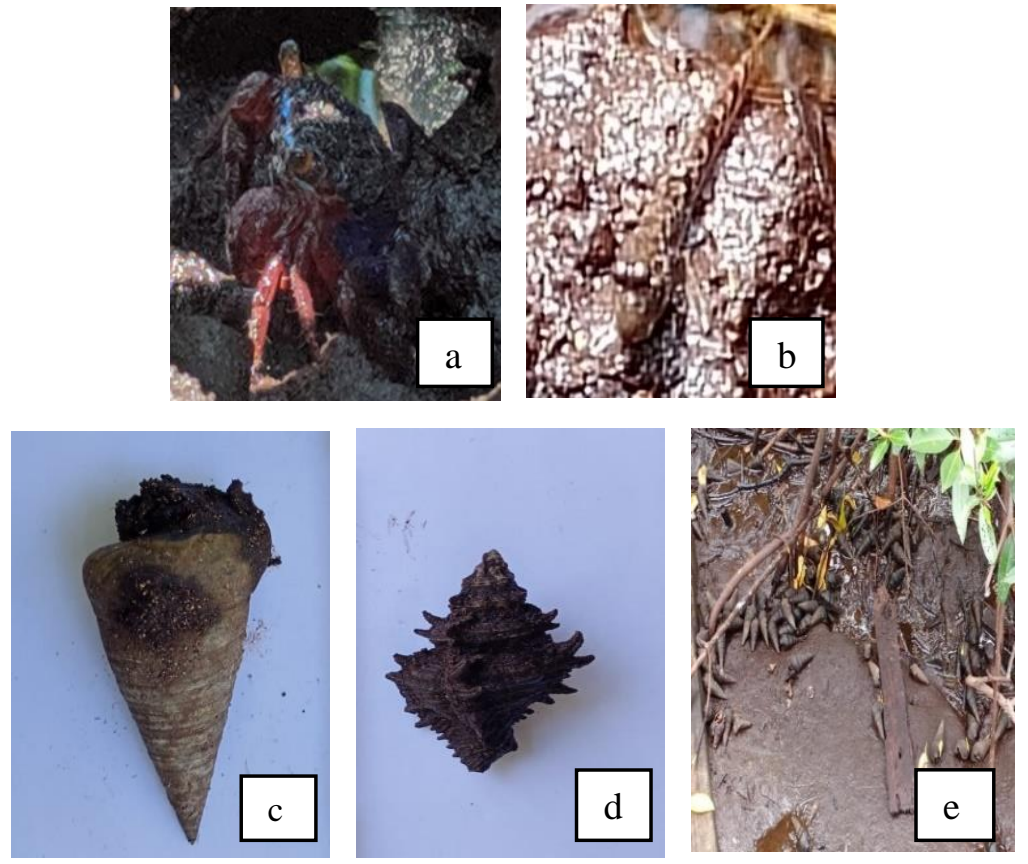

Figure 6. Type of biota found in mangrove ecosystem (a) Metaplax sp., (b) Periophthalmus sp., (c) Telecopium telescopium, (d) Chicoreus capucinu, (e) Cerithidea cingulata.

\subsection{Kesesuaian Ekosistem Mangrove untuk Pengembangan Ekowisata}

Penentuan kawasan untuk dijadikan suatu objek wisata harus didasari dari penilaian kawasan yang memiliki pertimbangan parameter tertentu agar kawasan tersebut layak menjadi objek wisata yang berkelanjutan. Paramater yang dimaksud mengacu pada Yulianda (2019), terdiri dari ketebalan mangrove $(\mathrm{m})$, kerapatan mangrove (ind/ $\mathrm{m}^{2}$ ), pasang surut $(\mathrm{m})$, objek biota. Secara spasial kesesuaian ekowisata mangrove disajikan pada (Figure 7).

Dari hasil perhitungan kelima parameter dalam kesesuaian ekowisata mangrove di Pulau Pannikiang, menjelaskan beberapa titik stasiun penelitian masuk dalam kategori sangat sesuai dan sesuai untuk ekowisata mangrove. IKW di lokasi penelitian dengan kategori sangat sesuai 6,73 ha dan 22,03 ha yang masuk dalam kategori sesuai sehingga total IKW yang diperoleh 28,76 ha. Hampir keseluruhan Pulau Pannikiang masuk dalam kategori sesuai dengan pertimbangan kriteria scoring yang didapatkan dalam matriks kesesuaian dan hanya pada titik dekat sebelah selatan pulau yang masuk dalam kategori sangat sesuai dengan nilai yang diperoleh 2,5 berdasarkan kriteria matriks kesesuaian Yulianda (2019).

\subsection{Daya Dukung Kawasan (DDK)}

Mengingat tingkat kerentanan dan ruang yang terbatas untuk pengunjung maka perlu ditentukan daya dukung kawasan. Daya dukung ini sifatnya adalah keberlanjutan yang berada pada posisi sumber daya yang berkelanjutan. Perhitungan daya dukung kawasan berperan penting untuk menekan pemanfaatan yang berlebihan juga tetap. Berdasarkan hasil perhitungan yang telah dilakukan diperoleh panjang garis pantai kawasan Pulau Pannikiang yang sesuai untuk ekowisata mangrove adalah 1793,45 m (Lp) dengan total luas mangrove yang sesuai (kategori sesuai dan sangat sesuai) adalah 2524,65 m. Panjang garis pantai yang sesuai untuk ekowisata diasumsikan sebagai tracking untuk kegiatan wisata (Lp). Menurut Yulianda (2019), potensi ekologis pengunjung $(\mathrm{K})$ persatuan unit area untuk wisata mangrove adalah 1 


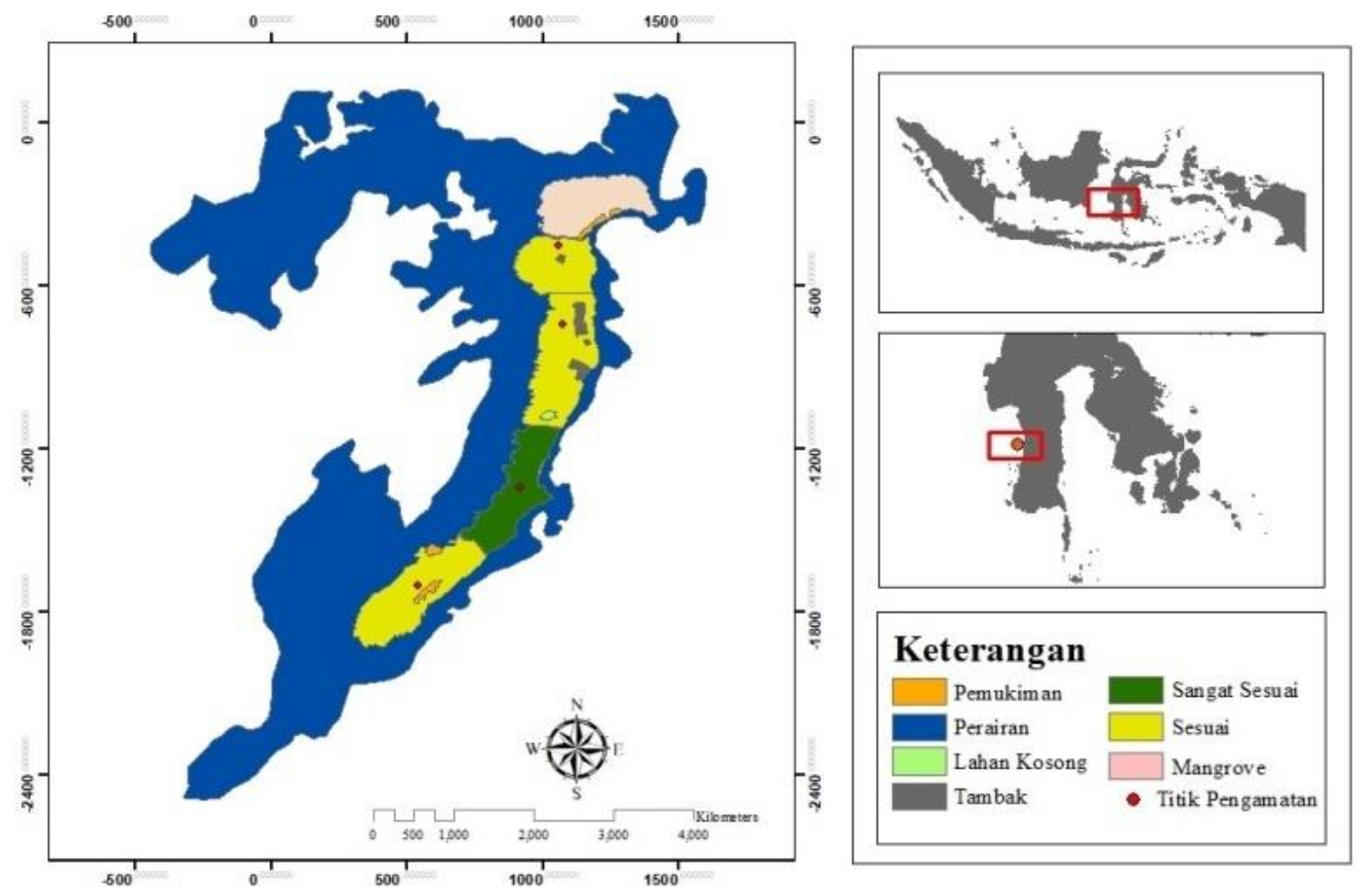

Figure 7. Map of the suitability of mangrove ecotourism.

orang untuk tracking $25 \mathrm{~m}$ (Lt). Waktu yang dihabiskan oleh setiap pengunjung adalah 2 jam (Wp). Lama waktu yang disediakan oleh kawasan untuk berwisata satu hari adalah 8 jam (Wt). Dengan demikian, nilai yang didapatkan untuk perhitungan daya dukung kawasan ekosistem mangrove untuk ekowisata di Pulau Pannikiang adalah 287 orang/hari pada area S1 dan S2. Berdasarkan wawancara dengan pihak terkait mengatakan bahwa rata-rata jumlah kunjungan wisatawan adalah 50-100 orang/bulan. Artinya, kapasitas daya tampung wisatawan untuk menikmati keindahan di Pulau Pannikiang masih dalam kategori baik. Dengan konsep ini, mampu menekan terjadinya kerusakan sumber daya alam dan lingkungan serta pihak pengelola juga memiliki peran penting dalam pembatasan jumlah wisatawan ketika sudah melebihi ambang batas maksimal yang diperbolehkan agar kenyamanan wisatawan tetap terjaga. Kondisi saat ini, jalur tracking mangrove sebagian mengalami kerusakan dan belum terhubung dalam satu kawasan. Tracking mangrove hanya tersedia di bagian utara dan pertengahan pulau, sehingga nantinya jumlah daya dukung wisatawan dapat bertambah jika jalur tracking dalam satu kawasan sudah terhubung.

\section{KESIMPULAN}

Kesesuaian wisata sangat penting untuk menilai pengembangan wisata mangrove dalam pemanfaatan sumber daya alam dan lingkungan. Potensi ekosistem mangrove yang masih alami di Pulau Pannikiang sangat tepat untuk dilakukan penilaian kesesuaian agar tidak terjadi pemanfaatan sumber daya yang dapat merusak lingkungan, sehingga berpotensi dikembangkan sebagai ekowisata. Ekosistem mangrove Pulau Pannikiang memiliki kategori IKW bervariasi yaitu kategori sangat sesuai 6,73 ha dan kategori sesuai 22,03 ha sehingga total IKW yang diperoleh 28,76 ha dengan daya dukung 287 orang/hari. Dengan konsep ini, pihak pengelola memiliki peran penting 
dalam pembatasan jumlah wisatawan ketika sudah melebihi ambang batas maksimal yang diperbolehkan agar kenyamanan wisatawan tetap terjaga.

\section{UCAPAN TERIMA KASIH}

Terima kasih kepada Dinas Kelautan dan Perikanan Provinsi Sulawesi Selatan, Dinas Perikanan Kabupaten Barru, Dinas Pariwisata dan beberapa instansi terkait yang telah memberikan dukungan untuk penelitian tentang pengembangan ekowisata mangrove di Pulau Pannikiang.

\section{DAFTAR PUSTAKA}

Bengen, D.G. 2001. Pedoman teknis pengenalan dan pengelolaan ekosistem mangrove. Pusat Kajian Sumberdaya Pesisir dan Lautan, IPB. Bogor. 58 p.

Buckley, R. 2004. Environmental impact of ecotourism. Ecotourism series No.2. Environmental Impacts of Ecotourism, Cambridge: CABI Publishing. 403 p.

Dinas Perikanan Kelautan Provinsi Sulawesi Selatan dan Universitas Muslim Indonesia. 2012. Laporan Akhir Identifikasi dan Pemetaan Potensi Sumberdaya Pulau Pannikiang Kabupaten Barru. Makassar. Dinas Kelautan Perikanan. Provinsi Sulawesi Selatan. 105 p.

Food and Agriculture Organization (FAO). 2007. The world's mangroves 19802005. Rome: Food and Agriculture Organization of the United Nations. $153 \mathrm{p}$.

http://www.fao.org/3/ap428e/ap428e 00.pdf

Friess, D.A. 2016. Ecosystem services and disservices of mangrove forests: Insights from historical colonial observations. Forests, 7(9): 1-16. https://doi.org/10.3390/f7090183

Gigović, L., D. Pamučar, D. Lukić, \& S. Marković. $\quad 2016 . \quad$ GIS-Fuzzy
DEMATEL MCDA model for the evaluation of the sites for ecotourism development: A case study of "Dunavski ključ" region, Serbia. Land Use Policy, 58: 348-365. https://doi.org/10.1016/j.landusepol. 2016.07.030

Giri, C., E. Ochieng, L.L. Tieszen, Z. Zhu, A. Singh, T. Loveland, J. Masek, \& N. Duke. 2010. Status and distribution of mangrove forests of the world using earth observation satellite data. Global Ecology and Biogeography, 20(1): 154-159. https://doi.org/10.1111/j.14668238.2010.00584.x

Heriyanto, N.M. \& E. Subiandono, 2012. Komposisi dan struktur tegakan, biomasa, dan potensi kandungan karbon hutan mangrove di Taman Nasional Alas Purwo. J. Penelitian Hutan dan Konservasi Alam, 9(1): 023-032.

https://doi.org/10.20886/jphka.2012. 9.1.023-032

Honey, M. \& D. Krantz. 2007. Global trends in coastal tourism. Washington: Stanford University and Center on Ecotourism and Sustainable Development. 140 p.

Hossain, M.S., R.C. Sayedur, G.D. Nani, S.M. Sharifuzzaman, \& S. Abida. 2008. Integration of GIS and multicriteria decision analysis for urban aquaculture development in Bangladesh. Landscape and Urban Planning, 90(3): 119-133. https://doi.org/10.1016/j.landurbplan. 2008.10.020

Kalogirou S. 2001. Expert system and GIS: an application of land suitability evaluation. computers. Environment and Urban Systems, 26(2): 89-112. https://doi.org/10.1016/S01989715(01)00031-X

Kathiresan, K. \& B.L Bingham. 2001. Biology of mangroves and mangrove ecosystems. Advances in Marine 
Biology, 40: 81-251.

http://doi.org/10.1016/s0065-

2881(01)40003-4

Nagelkerken, I., S.J.M. Blaber, S. Bouillon, P. Green, M. Haywood, L.G. Kirton, J.O. Meynecke, J. Pawlik, H.M. Penrose, A. Sasekumar, \& P.J. Somerfield. 2008. The habitat function of mangroves for terrestrial and marine fauna: A review. Aquat. Bot., 89(2): 155-185.

https://doi.org/10.1016/j.aquabot.200 7.12.007

Noor, Y.R., M. Khazali, \& I. N.N. Suryadiputra. 1999. Panduan Pengenalan Mangrove di Indonesia. Ditjen PHKA dan Wetlands International Indonesia Programe. Bogor. 220 p.

Pariwono, J.I. 2007. Pasang surut dan salinitas: dua parameter oseanografi yang efektif namun masih terabaikan dalam program penyusunan kebijakan kelautan Indonesia. Prosiding: 2783: 38-47.

http://repository.ipb.ac.id/handle/123 456789/51775

Qamal, A.I.R. 2019. Perubahan luas dan kerapatan hutan mangrove Pulau Pannikiang, Kabupaten Barru. $J$. Environmental Science, 1(2): 1-7. https://ojs.unm.ac.id/JES/article/view 19054

Rakotomavo, A. \& F. Fromard. 2010. Dynamics of mangrove forests in the Mangoky River delta, Madagascar, under the influence of natural and human factors. Forest Ecology and Management, 259(6): 1161-1169. https://doi.org/10.1016/j.foreco.2010 .01 .002

Rini, I. Setyobudiandi, \& M.M. Kamal. 2018. Kajian kesesuaian, daya dukung dan aktivitas ekowisata di Kawasan Mangrove Lantebung Kota Makassar. J. Pariwisata, 5(1): 1-10. https://doi.org/10.31311/par.v5i1.317 9
Rusdi, R., I. Setyobudiandi, \& A. Damar. 2020. Kajian potensi dan pengelolaan berkelanjutan ekosistem mangrove Pulau Pannikiang, Kabupaten Barru, Sulawesi Selatan. J. Ilmu dan Teknologi Kelautan Tropis. 12(1): 119-133. http://doi.org/10.29244/jitkt.v12i1.26 065

Romañach, S.S., D.L. DeAngelis, H.L. Koh, Y. Li, S.Y. Teh, R.S. Raja Barizan, \& L. Zhai. 2018. Conservation and restoration of mangroves: Global status, perspectives, and prognosis. Ocean \& Coastal Management, 154(2018): 72-82.

https://doi.org/10.1016/j.ocecoaman. 2018.01.009

Sadik, M., A.H. Muhiddin, \& M. Ukkas. 2017. Kesesuaian ekowisata mangrove ditinjau dari aspek biogeofisik kawasan pantai gonda di Desa Laliko Kecamatan Campalagian Kabupaten Polewali Mandar, J. Ilmu Kelautan SPERMONDE Universitas Hasanuddin, 3(2): 25-33. http://doi.org/10.20956/jiks.v3i2.300 4

Samsi, A.N., S.B.N. Omar, \& A. Niartiningsih. 2018. Pengaruh faktor lingkungan terhadap pola penyebaran moluska pada ekosistem mangrove alami dan hasil rehabilitasi. Fish Scientiae: J. Ilmu-ilmu Perikanan dan Kelautan, 8(1): 5160.

http://fishscientiae.ulm.ac.id/index.p $\mathrm{hp} / \mathrm{fs} /$ article/view/131

Samsi, A.N., S.B.N. Omar, \& A. Niartiningsih. 2018. Analisis kerapatan ekosistem mangrove di Pulau Pannikiang dan Desa Tongke-tongke Sulawesi Selatan. J. Biota, 4(1): 1923.

https://doi.org/10.19109/Biota.v4i1.1 593

Shoo, R.A \& A.N. Songorwa. 2013. Contribution of eco-tourism to nature 
conservation and improvement of livelihoods around Amani nature reserve, Tanzania. J. Ecotourism, 12(2): 75-89.

https://doi.org/10.1080/14724049.20 13.818679

Spalding, M. \& C.L. Parrett. 2019. Global patterns in mangrove recreation and tourism. Marine Policy, 110(103540): 1-8. https://doi.org/10.1016/j.marpol.201 9.103540

Surjanti, J., A. Soejoto, D.N. Seno, \& Waspodo. 2020. Mangrove forest ecotourism: Participatory ecological learning and sustainability of students' behavior through selfefficacy and self-concept. Social Sciences \& Humanities Open, 2(1): 1-6. https://doi.org/10.1016/j.ssaho.2019. 100009

Susi, W. Adi, \& S.P. Sari. 2018. Potensi kesesuaian mangrove sebagai daerah ekowisata di Dusun Tanjung Tedung Sungai Selan Bangka Tengah. Akuatik: J. Sumberdaya Perairan, 12(1): 65-73. https://doi.org/10.33019/akuatik.v12i 1.693

Suwardi, E. Tambaru, Ambeng, \& D. Priosambodo. 2013. Keanekaragaman jenis mangrove di Pulau Pannikiang Kabupaten Barru
Sulawesi Selatan. Jurusan Biologi Fakultas Matematika dan Ilmu Pengetahuan Alam Universitas Hasanuddin Makassar. https://core.ac.uk/download/pdf/2549 5489.pdf

Veettil, B.K., R.D. Ward, N.X. Quang, \& N.T.T. Trang. 2019. Mangroves of Vietnam: Historical development, current state of research and future threats. J. Estuarine, Coastal and Shelf Science, 218: 212-236. https://doi.org/10.1016/j.ecss.2018.1 2.021

Wardhani, M.K. 2011. Kawasan konservasi mangrove: Suatu potensi ekowisata. J. Kelautan, 4(1): 60-76. https://journal.trunojoyo.ac.id/jurnal kelautan/article/view/891/784

Yulianda, F. 2019. Ekowisata Perairan Suatu Konsep Kesesuain dan Daya Dukung Wisata Bahari dan Wisata Air Tawar. IPB Press. Bogor. 84 p.

Yulius, R. Rahmania, U.R. Kadarwati, M. Ramdhan, T. Khairunnisa, D. Saepuloh, J. Subandriyo, \& A. Tussadiah. 2018. Buku panduan kriteria penetapan zona ekowisata bahari. IPB Press. Bogor. 155 p.

Received :6 March 2020

Reviewed : 24 March 2020

Accepted : 1 December 2020 